\title{
El laberinto religioso de Juan Manuel de Rosas
}

\author{
Roberto Di Stefano
}

CONICET- Facultad de Filosofía y Letras, Universidad de Buenos Aires

La historiografía tradicional argentina consolidó la imagen de Juan Manuel de Rosas como el restaurador de la tradición católica colonial, muy debilitada durante la experiencia rivadaviana en la década de 1820. Este trabajo cuestiona tal posición. Nuestra hipótesis central es, por el contrario, que Rosas trató de implementar una política religiosa inspirada en elementos provenientes de distintas tradiciones ideológicas. Este intento lo condujo a un callejón sin salida.

Palabras Clave: Juan Manuel de Rosas, Política religiosa, Reforma eclesiástica.

Argentine traditional historiography consolidated the imagen of Juan Manuel de Rosas as the Restorer of the colonial Catholic tradition strongly weakened during the Rivadavian experience on the decade of 1820. This work discusses this assumption. Our central hypothesis is, on the contrary, that Rosas tried to carry out a religious policy inspired in distinct elements taken of different ideological traditions. This attempt conducts him to a dead-end.

KeYwords: Juan Manuel de Rosas, Religious Policy, Ecclesiastical Reform.

En 1820, incapaz de resistir los embates de la guerra civil, terminó de desmoronarse el Directorio que gobernaba —o más bien intentaba gobernar- a las Provincias Unidas del Río de la Plata, aún insurrectas contra España. Lo que emergió de sus ruinas fue un conjunto de estados provinciales soberanos que a partir de entonces buscaron ejercer plena jurisdicción sobre los habitantes que poblaban sus geografías. De todas esas experiencias de gobierno provincial la más exitosa fue sin dudas la de Buenos Aires, ciudad que había alcanzado ya a fines del siglo XVIII las dimensiones de una urbe española de segundo orden, gracias a su intenso dinamismo demográfico y a su activo comercio, y que desde 1776 ostentaba el rango de capital virreinal. Las profundas transformaciones que se produjeron en las instituciones eclesiásticas y en la vida religiosa porteñas 
durante el pasaje del orden colonial a la vida independiente han sido analizadas por diferentes autores y siguen siendo motivo de estudio y debate. ${ }^{1}$ Sin embargo, los estudios de historia colonial y del primer siglo XIX raramente se han aventurado más allá del año 1830, cuando sin duda la vida de la Iglesia experimenta un giro, por lo que las décadas centrales de la centuria permanecen prácticamente vírgenes en cuanto a lo que investigación se refiere.

El presente artículo intenta esa aventura: se centra en la experiencia de gobierno de Juan Manuel de Rosas durante la década de 1830, período que abarca su primera gestión como gobernador de la provincia (1829-1832) y el primer tramo de su segundo mandato (1835-1839). La crisis en que se precipitó el gobierno federal a partir de 1838 marcó un viraje en diferentes planos, incluido el eclesiástico, por lo que los años sucesivos deberán ser objeto de un ulterior estudio. La hipótesis central de este trabajo es que Rosas intentó implementar durante el período examinado una política religiosa inspirada en elementos provenientes de tradiciones ideológicas incompatibles: heredero por un lado de la tradición galicana consagrada en la Ley de Reforma del Clero de 1822 y, por otro, de convicciones intransigentes incompatibles con ella, el gobernador buscó conservar el andamiaje institucional reformista introduciendo en él modificaciones que por su misma naturaleza estaban destinadas al fracaso. Esa política eclesiástica condujo al gobierno federal a un laberinto del que no logró nunca encontrar la salida. Su voluntad de conservar en sus lineamientos esenciales el modelo reformista de la década de 1820 era no sólo contradictoria sino inconciliable con las modificaciones que intentó introducir en él, en particular la transferencia de recursos del clero secular a la única orden religiosa que logró sobrevivir a la reforma - los franciscanos- y a las que Rosas hizo resucitar entre 1835 y 1836 (dominicos y jesuitas). El progresivo desinterés que desde 1839 el gobernador parece manifestar por la Iglesia como instrumento para la conservación y la reproducción del orden federal es indicio, tal vez, del peso de ese fracaso. Secundariamente y en otro registro, el artículo intenta poner en discusión una imagen de Rosas que la historiografía, desde la obra pionera de Adolfo Saldías hasta algunos aportes relativamente recientes como los de John Lynch, ha transmitido de genera-

1 Entre los estudios recientes más específicos cabe señalar Peire, J.: El taller de los espejos, Iglesia e imaginario, 1767-1815, Claridad, Buenos Aires, 2000, y Di Stefano, R.: El púlpito y la plaza. Clero, sociedad y política de la monarquía católica a la república rosista, Siglo XXI, Buenos Aires, 2004. 
ción en generación: la de Rosas como restaurador de la tradición católica colonial debilitada durante la experiencia rivadaviana de la década de 1820 . En este segundo plano, el trabajo sintoniza con la obra de otros historiadores que han señalado antes que su autor el carácter erróneo de esa interpretación, que lo es además por el hecho de que tiende a considerar al régimen de Rosas como un bloque, cuando es claro que ese régimen — según la feliz expresión de Jorge Myers- fue construyéndose gradualmente y "por parches". ${ }^{2}$ Puesto que el marco inicial en el que Rosas actúa es el diseñado por la reforma de 1822, ofreceré antes que nada un breve análisis de la ingeniería eclesiástica plasmada en ella. Explicaré y analizaré luego los motivos que movieron a Rosas a respetar ciertos rasgos de esa política y a introducirle algunas significativas modificaciones, dando forma a una política eclesiástica destinada al fracaso.

\section{El sueño reformista}

En cierto sentido, durante la época colonial no existió una "Iglesia" en el sentido que actualmente se da al término, sentido que implica, por un lado, la existencia de una institución dotada de un grado suficiente de autonomía en la formulación de sus objetivos y sus estrategias y en la elaboración de su discurso y, por otro, su estructuración a partir de un único centro de autoridad capaz de lograr que la totalidad de sus miembros acaten sus directivas por medio del consenso o por medio de la coacción. ${ }^{3}$ La llamada "Iglesia colonial", lejos de ello, era un conjunto heterogéneo de instituciones muy diferentes, en muchos casos demasiado dependientes de los intereses de familias específicas y redes de la elite, y sus objetivos y estrategias eran formulados en muy buena medida por la Corona española a través del ejercicio del derecho de patronato. En Buenos Aires la construcción de una institución eclesiástica, proceso contemporáneo y estrechamente

2 T. Halperin Donghi señaló significativas continuidades entre la política de Rosas y la del "partido" rivadaviano, incluso en el plano eclesiástico, en: Halperin Donghi, Tulio: De la revolución de independencia a la confederación rosista, Paidós, Buenos Aires, 1972. Más recientemente, J. Myers ha advertido acerca del lugar secundario que los temas religiosos ocuparon dentro del universo discursivo del rosismo Myers, J.: Orden y virtud. El discurso republicano en el régimen rosista, Universidad Nacional de Quilmes, Bernal, 1995.

3 Véase la voz "Istituzione" en Esposito, R. y Galli, C. (dir.): Enciclopedia del pensiero politico. Autori, concetti, dottrine, Laterza, Roma-Bari, 2000. Estas ideas han sido presentadas por primera vez en Di Stefano: El púlpito y... 
vinculado al de la formación del Estado provincial que tiene lugar luego de 1820, tendió a separar a las instituciones eclesiásticas coloniales y al clero del universo de intereses familiares que los sustentaba y reproducía, así como a centralizar sus múltiples instancias de toma de decisiones subordinándolas a la autoridad diocesana. El momento crucial en ese camino fue la Ley de Reforma del Clero sancionada por la Legislatura en diciembre de 1822, parte fundamental del programa más general de reformas con el que el elenco gobernante buscaba moldear diferentes ámbitos de la vida porteña, poniéndolos, como se dice, "a la altura de los tiempos". ${ }^{4}$ Esa reforma eclesiástica, siguiendo a grandes rasgos el modelo de la Constitución Civil del Clero de Francia de 1790, confirió por un lado a las instituciones eclesiásticas una organización unitaria y, por otro, al incorporarlas a la estructura político-administrativa del Estado en formación, buscó introducir una cuña entre ellas y la sociedad que las había creado y reproducido hasta entonces. Subrayo el carácter tendencioso de esa política: no afirmo sin más que la participación de las familias de elite en la vida de la Iglesia desapareció desde entonces, ni que se haya eliminado completamente la poliarquía eclesiástica, sino simplemente que en tal sentido obraba el proyecto reformista. Mientras el éxito fue completo en relación con la construcción de un polo único de la toma de decisiones, la participación de las familias en las instituciones trasladadas al ámbito del Estado mudó su naturaleza: a partir de entonces ellas perdieron la posibilidad de incidir de manera determinante en las decisiones cruciales para la vida de parroquias, conventos y otras instituciones.

De manera esquemática puede decirse que los ejes fundamentales de la Reforma del Clero implicaban la transferencia de recursos humanos y materiales del clero regular al secular, pensado como clero de la provincia y no ya de la entera diócesis, que comprendía además las provincias de Entre Ríos, Santa Fe, Corrientes y la Banda Oriental, que en 1828 se independizó políticamente como República Oriental del Uruguay. Ejemplos de esa transferencia son la promoción de las secularizaciones de frailes, o las confiscaciones de instalaciones de los conventos por parte de la diócesis y del Estado. La reforma implicaba además la ruptura o, al menos, el debilitamiento de los lazos de dependencia de las instituciones eclesiásticas con

4 Sobre el programa general de reforma, Ternavasio, M.: "Las reformas rivadavianas en Buenos Aires y el Congreso General Constituyente (1820-1827)", en Goldman, N. (dir.): Revolución, República, Confederación (1806-1852), vol. III de Nueva Historia Argentina, Editorial Sudamericana, Buenos Aires, 1998, págs. 159-197. 
respecto a familias muy concretas. Conllevaba la centralización de la toma de decisiones en el ordinario, en este caso el cabildo eclesiástico, rebautizado con el título algo pomposo de Senado del Clero. Importaba, por último, la sujeción del sistema entero a los poderes del Estado provincial. Se trataba de la construcción de una Iglesia de base provincial adaptada al modelo de Estado republicano que en esos mismos años se intentaba instaurar. Iglesia y Estado no fueron en el Río de la Plata, como en ningún otro sitio, entidades atemporales en lucha desde tiempos inmemoriales, sino dos estructuras que se construyeron históricamente. En el caso rioplatense al menos, esa construcción se verificó más bien en estrecha relación e interacción entre ambas partes que como el resultado de la pugna entre dos ámbitos con finalidades opuestas.

El grupo reformista buscó remodelar la vida eclesiástica dentro de la horma republicana. La transferencia de recursos del clero regular al secular tenía el sentido de "homogeneizar" al clero, eliminando en lo posible la estructura estamental eclesiástica heredada del antiguo régimen e intentando, a la vez, que la totalidad de las actividades cultuales y pastorales fuesen confiadas a los clérigos. Éstos, por sus características, podían asimilarse política y conceptualmente mucho mejor a la sociedad jurídicamente igualitaria soñada por el círculo rivadaviano. La eliminación del fuero eclesiástico obraba en el mismo sentido. Un artículo de El Centinela de 1822 explicaba que todo eclesiástico "se presenta a nuestra vista bajo dos aspectos: como ciudadano y como ministro del altar". Además, como "por la naturaleza misma del poder temporal, las excepciones del clero resisten a la autoridad de aquel", la eliminación del fuero permitiría el renacimiento de "aquel espíritu de igualdad que animaba a los primeros fieles". 5

La existencia de órdenes religiosas comportaba en cambio una fragmentación de la obediencia que el nuevo elenco gobernante y sus partidarios juzgaban intolerable. Cada una de ellas poseía sus "súbditos", ligados a sus superiores por un lazo de obediencia sancionado solemnemente como voto religioso, en contradicción con la imagen del ciudadano libre para elegir y ser elegido en la arena política "moderna". Por otra parte, la existencia de órdenes implicaba la existencia de una fragmentación devocional, es decir, la convivencia de diferentes sensibilidades y representaciones que sancionaban en el plano mental la fragmentación de la obediencia. La eli-

5 El Centinela, 11 de agosto de 1822. 
minación de los conventos implicaba la de la poliarquía espiritual del Antiguo Régimen. Con el modelo de Iglesia propuesto, el gobierno buscaba centralizar la vida devocional y vincularla al imaginario republicano. La reducción a la unidad en ese plano se refleja, por ejemplo, en la celebración conjunta de la fiesta de Corpus Christi y el primer aniversario de la Revolución luego de la reforma. ${ }^{6}$ Si hasta 1821 los gastos habían corrido por cuenta del Cabildo, la eliminación de la corporación —que superponía su jurisdicción a la del naciente Estado provincial- permitió que desde entonces se considerase a la fiesta como "primera función del Estado". ${ }^{7} \mathrm{La}$ misma tendencia se advierte en la política "utilitarista" seguida en relación con el Santuario de Luján, que a los ojos del gobierno no tenía "mas objeto que el culto de una imagen" que le permitía a su parroquia recaudar "una cantidad de emolumentos superior à la de casi todas las parroquias de campaña". ${ }^{8} \mathrm{O}$ en la creación del cementerio público que eliminó la fragmentación de los espacios de la muerte. ${ }^{9}$ La centralización de la Iglesia republicana aconsejaba reducir al mínimo la pluralidad de expresiones de devoción coloniales, reflejo espiritual de antiguas vinculaciones y obediencias sobre las que se habían sustentado las tradicionales instancias del poder político-religioso.

La centralización además, como se ha dicho, implicaba el debilitamiento de los vínculos entre familias e instituciones eclesiásticas, que con la reforma pasaron a considerarse sin más estructuras administradas por el Estado. Las parroquias fueron consideradas patrimonio de las comunidades de fieles en su conjunto, y la designación del párroco y de los síndicos dejó de ser (al menos en las intenciones) el fruto de un acuerdo entre el poder civil y las familias que habían construido y mantenían el templo (a veces se trataba del patronato de una única familia). ${ }^{10}$ En 1822 los síndicos pasaron a ser nombrados exclusivamente por el gobierno, si bien en

6 Véase el intercambio de cartas entre el presidente interino del senado del clero y el gobernador en mayo de 1823 en Archivo General de la Nación, Estado de Buenos Aires (en adelante AGN), Culto, X 4-8-4: 1823.

7 Así lo expresa Andrés F. Ramírez en carta al ministro de gobierno de 8 de junio de 1824 , en AGN, Culto, X 4-8-5, 1824-1826.

8 Registro Oficial de la Provincia de Buenos Aires, 1822, decreto 376 del 1 de julio de 1822. de 1821 .

9 Registro Oficial de la Provincia de Buenos Aires, 1821, decreto 109 del 13 de diciembre

10 Existen varios casos que he documentado en Di Stefano: El púlpito y la plaza ..., cap. 2. Las leyes de Indias establecían que "si algun particular fundare Iglesia, u obra pia, tenga el Patronazgo de ella, y los Prelados la jurisdicción que les da él derecho." Recopilación de Leyes de los Reynos de Indias, t. I, Libro I, Título VI, Ley xxxxiij, Consejo de la Hispanidad, Madrid, 1943. 
la práctica se acostumbró pedir a los párrocos que sugirieran un nombre. ${ }^{11}$ $\mathrm{Si}$ en la época colonial había sido intensa la influencia de esas familias sobre aspectos centrales de la vida de las instituciones religiosas, al ser éstas incorporadas a la órbita del poder público, esa incidencia tendía a debilitarse o a reformularse en términos mucho más mediatizados. Con ello se daba cumplimiento a un antiguo anhelo borbónico, expresado, por ejemplo, en la prohibición de los entierros en las iglesias y la formación de cementerios fuera de ellas; independientemente de los motivos sanitarios aducidos, sin duda atendibles, la medida apuntaba a lograr una mayor distinción entre la Iglesia y la sociedad. En la reforma porteña de 1822, la eliminación de los diezmos y el proyecto de que la totalidad de los ministros del culto y los párrocos pasaran a cobrar sueldos del Estado obraba en el mismo sentido: desvincular, cortar o al menos debilitar al máximo los lazos de dependencia que mutuamente ligaban al clero a las instituciones eclesiásticas y a la sociedad. Por eso es que a partir de esos años se consideró "subversiva" la mendicidad de los religiosos, más allá de que sirviera, de paso, como elemento de presión para obligarlos a optar por la secularización.

El sistema de gobierno de esa Iglesia republicana quedaba en manos fundamentalmente del Senado del Clero, instancia colegiada que reflejaba, en el plano eclesiástico, el poder soberano que ejercía la legislatura provincial. El prelado gobernador de la diócesis, que permanecía en sede vacante desde 1812, funcionaba como una especie de Poder Ejecutivo que ejercía sus poderes como delegado del Senado. Éste, a su vez, detentaba una suerte de "soberanía religiosa" que nacía del pueblo cristiano porteño, obvia aplicación al plano eclesiástico de las ideas vigentes en la esfera política en relación con la soberanía popular. La centralización de la obediencia barría con la poliarquía eclesiástica propia del antiguo régimen. La sujeción de todas las autoridades religiosas al ordinario diocesano obraba en ese sentido, así como la eliminación (en la práctica) de las órdenes y otras instituciones, como la Vicaría General Castrense, abolida por tratarse de "una institución, que tanto perjudica à las ventajas de la uniformidad". ${ }^{12}$ Esa reducción a la unidad se debía dar en todos los niveles, incluso dentro

11 Registro Oficial de la Provincia de Buenos Aires, 1822, decreto 318 del 18 de marzo de 1822 . Véase También el decreto N. ${ }^{\circ} 345$ de 13 de abril del mismo año, en que se establece que "no reconocerán cargo alguno contra los ramos de su administración, sin declaracion especial del gobierno".

12 Registro Oficial de la Provincia de Buenos Aires, 1822, decreto 750 del 1 de julio de 1822. 
de las mismas parroquias, en las que se eliminó la antigua práctica de que coexistieran dos curas con idénticas o paralelas jurisdicciones. ${ }^{13}$

La Iglesia porteña se concebía como espacio de vida espiritual de los nuevos ciudadanos que el Estado buscaba formar a través del ejercicio de la vida política y de la participación en una esfera pública que simultáneamente se intentaba crear desde el Estado mismo. La nueva Iglesia porteña debía ser el ámbito en el que los ciudadanos del nuevo Estado celebraran el culto al Ser Supremo y las gestas libradas en la lucha por la libertad de la república. Los considerandos del decreto que en 1821 ordenó la reedificación de la catedral comienzan haciendo alusión a la gratitud que la república debe a Dios por la conquista de la independencia. ${ }^{14}$ Esta concepción se expresaba en signos exteriores que podían resultar irritantes tanto a los cristianos de tendencia liberal — católicos o protestantes- como a los católicos más intransigentes. La Iglesia republicana ostentaba como trofeos las armas capturadas por sus ciudadanos a los opresores derrotados. El autor inglés de Cinco años en Buenos Aires dejó sentado su disgusto por el hecho de que "los emblemas pacíficos de los altares" estuviesen "oscurecidos por las insignias guerreras ubicadas en la parte superior de la nave. Penden del techo cerca de veinte banderas capturadas a los españoles en varias ocasiones: Montevideo, Maipú, etc. El nombre de Fernando VII está inscripto en casi todas". ${ }^{15}$ Esa catedral, cuyo interior había comenzado a construirse en 1791 con otro estilo, fue dotada en esos mismos años de una fachada que le otorgaba la apariencia de un templo de la antigüedad clásica y que ha llegado hasta nuestros días con pocas modificaciones. ${ }^{16}$ Las doce columnas

13 Antes aún de la reforma el Provisor Valentín Gómez se había expresado al respecto en los siguientes términos: "Bastaria la idea general de que en un cuerpo no pueden hallarse sin monstruosidad dos cabezas, para conocer que en una Parroquia no deben haber dos Parrocos con igual dignidad, igual carácter, igual jurisdiccion, iguales prerrogativas, y derechos. Seria menester que la investidura que le da la institucion de sus beneficios los sacase de la condicion comun de todos los hombres, para esperar que a la larga no resultasen desavenciones, y discordias, que rompiendo los vinculos de la union, y buena inteligencia entre los pastores, los hiciese menos recomendables o menos utiles para la Grey". AGN, Culto, x 4-8-3, 1822. J. V. Gómez al ministro de gobierno, 18 de diciembre de 1821. noviembre.

14 Registro Oficial de la Provincia de Buenos Aires, 1821, decreto N. 70 del 10 de

15 Un inglés: Cinco años en Buenos Aires, 1820-1825, Hyspamérica, Buenos Aires, 1986, pág. 30.

16 Aliata, Fernando: "Cultura urbana y organización del territorio", en Goldman, N. (dir.): Revolución, república, confederación (1806-1852), t. III de Nueva Historia Argentina, Editorial Sudamericana, Buenos Aires, 1998, págs. 226-227. La satisfacción del cabildo eclesiástico con el frontis queda manifiesta en carta al gobierno del 7 de diciembre de 1821 al ministro de gobierno. Los canónigos, "llenos de gozo" dan gracias a Rivadavia "p[o]r su zelo, y p[o]r el afecto especial q[u]e manifiesta á esta Igles.a”. AGN, Culto, X 4-8-2, 1818-1821. 
que sostienen el frontis fueron pensadas para transmitir la imagen de la pluralidad de las Iglesias del orbe, claro reflejo arquitectónico de las convicciones galicanas del grupo político rivadaviano y del clero que apoyaba su modelo de Iglesia.

\section{De la Iglesia del orden a la Iglesia federal}

Los intensos debates que desató la reforma del clero produjeron una fractura en la elite porteña, que el congreso de 1824-1827 proyectó hacia el resto de las provincias y que guarda relación con el surgimiento de los partidos unitario y federal y la guerra civil. En efecto, esa confrontación política se expresó también en encontradas posiciones en materia religiosa: mientras el partido federal fue gradualmente identificándose con la "ortodoxia", el unitario no logró nunca desvincularse del todo - a pesar de los denodados esfuerzos realizados en ese sentido por algunas de sus más prominentes figuras - de la identificación de su causa con las "novedades" en cuestiones eclesiásticas. En ese contexto de progresiva polarización de las posiciones políticas y de las controversias entre posiciones incompatibles en materia religiosa, Rosas debió hacerse cargo del gobierno de la provincia en diciembre de 1829. Entre sus opciones políticas más importantes figura el apoyo otorgado al grupo católico intransigente que se conformara en oposición a la reforma del clero, grupo que en la segunda mitad de la década se había ido acercando cada vez más claramente al partido federal. Con ese apoyo Rosas buscaba desactivar el poder del Senado del Clero, cuyas figuras más conspicuas —el deán Diego Estanislao Zavaleta, el canónigo José Valentín Gómez - se hallaban vinculadas en mayor o menor medida al partido unitario. Vencedor de la pulseada en la arena política, Rosas logró ganarla en la religiosa por decreto, por medio del traspaso del gobierno de la diócesis de manos del Senado del Clero a las del obispo Mariano Medrano y el círculo intransigente que giraba en torno a su figura. Al hacerlo, Rosas dio el primer paso para realizar en el plano eclesiástico una concentración del poder análoga a la que a partir de su segundo mandato operaría en el terreno político: de las instancias colegiadas (la Legislatura en el plano político, el Senado del Clero en la Iglesia) la toma de decisiones tendió a concentrarse en las instancias "ejecutivas" (el gobernador en el plano político, el obispo en la Iglesia). Así, Rosas reforzó la tendencia a la concentración del poder religioso que constituía la base del 
modelo reformista, pero abandonando la lógica que en ese modelo asignaba el ejercicio del poder al Senado del Clero en el marco del Estado.

En tanto, en el plano de la vida pastoral y litúrgica, Rosas se demostró más activo que sus antecesores. Entre su primer mandato (1829-1832) y la primera fase del segundo (1835-1839) se advierte un significativo cambio de tono, cuyo análisis constituye el objeto central de este apartado. Como esbozo de una posible explicación de este cambio de actitud podríamos pensar que, luego del asesinato del caudillo riojano Juan Facundo Quiroga en 1835, Rosas adoptó una postura de progresivo endurecimiento para con sus enemigos en el segundo mandato. ${ }^{17}$ Pero existen otros elementos que vale la pena destacar, porque ponen en evidencia las contradicciones en que se debatía la política eclesiástica del Restaurador. Veamos someramente el desarrollo de los acontecimientos.

En 1829 las laceraciones de la guerra civil habían dejado sobre el tapete el problema de la movilización de una campaña que hasta entonces había desempeñado un papel más bien pasivo en las contiendas políticas. A la preocupación por hacer algo con ella se sumaban la indignación que en el antiguo partido federal urbano había provocado la pérdida de su líder, el gobernador Manuel Dorrego, y las posibles derivaciones de los triunfos que estaba cosechando el General Paz en el interior. ${ }^{18}$ Ese contexto turbulento explica los esfuerzos que durante su breve gobierno (de agosto a diciembre de 1829) Juan José Viamonte realizara para "pacificar" el mundo rural, cuya radicalización constituía, a sus ojos, el ingrediente más peligroso de una fórmula explosiva. Entre los pocos instrumentos con los que contaba el gobierno para apaciguarla figuraba, por supuesto, el clero rural, segmento del personal del Estado dotado de adecuados recursos discursivos para aconsejar el orden, así como de un tradicional "influjo" que las tormentas posrevolucionarias habían mellado pero no extinguido. Dado que la causa federal triunfante era considerada a la vez popular y devota, la prédica del clero se vislumbraba como un instrumento potencialmente eficaz en la tarea de devolver a esa campaña el orden perdido. Ya a fines de octubre de 1829, al llamar la atención del gobernador del obispado en relación con la influencia que sobre la moral de los pueblos ejercían las costumbres de los párrocos, el ministro de gobierno le expresó su convicción de que tal principio

17 Para el relato y análisis del proceso político remito al lector a Halperin Donghi: De la revolución..., págs. 338-379.

18 Halperin Donghi: De la revolución..., págs. 301-303. 
“...es hoy de una particular aplicacion en la camp[añ]a por el desorden q[ue] aun domina en ella; consecuencia deplorable de los vaivenes [ilegible] pasados..... ${ }^{19}$

Esa convicción subyace también en la orden con que se obligó al prelado a trasladar el mismo día al cura de San Fernando a la parroquia de San Vicente, amonestándolo de paso para que no volviera a descuidar "el exacto cumplimiento de los deberes sagrados que le impone su ministerio". ${ }^{20} \mathrm{La}$ respuesta que el gobernador de la diócesis elevó para dar cuenta de su acatamiento es también elocuente por su referencia al

“...laudable objeto que se proponia el Superior Govierno, para que los Señores Curas [...] se contragesen unicamente al desempeño de su alto ministerio, exortando á sus fieles al cumplimiento de sus deberes, á la Paz, y buena armonia que deben obserbar entre si, y á la obediencia y respeto á las autoridades constituidas, sin mesclarse en fomentar partidos que tanto degradaban á un eclesiastico, y asunto tan ageno de un verdadero Parroco". ${ }^{21}$

Entre la voluntad de capitalizar la movilización política y los resquemores que aconsejaban ponerle algún tipo de límite, al asumir el cargo en diciembre de 1829, Rosas apostará a la posibilidad de controlarla y encauzarla. En los escritos que datan de los años de su primer mandato es habitual encontrar la idea de que la recuperación del orden en el campo conlleva el devolverle a la religión el lugar primordial del que los unitarios la habían despojado. Esa obsesión es la que inspira a Rosas, por ejemplo, adoptan una fugaz actitud permisiva con relación a las opiniones políticas de los párrocos, así como manifestar un llamativo desvelo por el vigor de las prácticas religiosas. Sería erróneo interpretar esa actitud y ese desvelo como muestras de un deliberado "apoyo a la Iglesia", como quiere la interpretación de generaciones de historiadores, desde Adolfo Saldías hasta Cayetano Bruno y John Lynch. ${ }^{22}$ La idea de que Rosas "apoya a la Iglesia" pierde de vista que esa Iglesia para él, como gobernador, no representaba

19 AGN X 15-3-3, varios 1829, borrador de nota del gobierno del 29 de octubre de 1829.

20 AGN X 15-3-3, varios 1829, nota al provisor del 29 de octubre de 1829.

21 AGN X 1-3-3, nota del provisor al ministro de gobierno del 2 de noviembre de 1829.

22 Saldías, A.: Historia de la Confederación Argentina, t. I, Eudeba, Buenos Aires, 1968 [1. a ed. 1892], por ejemplo pág. 211; Bruno, C.: Historia de la Iglesia en la Argentina, vol. IX, Don Bosco, Buenos Aires, 1974, págs. 374 y ss.; Lynch, J.: Juan Manuel de Rosas, 1829-1852, Emecé, Buenos Aires, 1984, págs. 176-179. Propusieron sustancialmente la misma interpretación Gutiérrez, J. M.: "Las restauraciones religiosas en 1835-1841-1875”, Revista del Río de la Plata, t. XI, 1875, págs. 399-433; Mansilla, L. V.: Rozas: ensayo histórico-psicológico, Garnier, Paris, 1898; Ramos Mejía, J. M.: Rosas y su tiempo, Buenos Aires, 1907; Ingenieros, J.: "Las ideas coloniales y la dictadura de Rosas", Revista de Filosofía, V, 1916, págs. 256-299. 
más que uno de los segmentos del aparato del Estado más eficaces para disciplinar la campaña y normativizar las conductas. Rosas no "apoya a la Iglesia": simplemente pone ese segmento del Estado al servicio de su política de orden.

El interés que en esa primera etapa muestra el gobernador por la reconstitución de la disciplina y de los lazos de obediencia predomina claramente por sobre las exigencias de fidelidad partidaria. Es verdad que algunos de los curas que hace colocar en las parroquias del norte de la provincia —el área a la que presta mayor atención por haber sido más afectada por la guerra civil - se declaran incondicionales a su gobierno, como el nuevo párroco de San Pedro, Mariano Espinosa, que se declara sin ambages federal y alaba "la honrosa marcha, que lleva el Govierno Federal en lo Politico, en lo Moral, y en todos sus pasos" ${ }^{23}$ Es cierto también que durante esos mismos años el gobierno toma cuidadosa nota de las convicciones políticas de los vecinos importantes de la campaña, incluyendo por supuesto a los curas..$^{24}$ Es altamente probable, incluso, que algunos de los párrocos depuestos lo hayan sido no sólo por sus actitudes negligentes sino también a causa de sus preferencias partidarias. Pero en el discurso del gobierno no se les exige, como ocurrirá a partir de 1835, una incondicional identificación con el régimen: cuando Rosas le pide a su padrino José María Terrero, a la vez representante en la legislatura y provisor del obispado, la separación de los curas de Baradero y del Fortín de Areco, solicita su reemplazo por sacerdotes idóneos, aunque no necesariamente federales. ${ }^{25}$ El tipo de efecto que Rosas espera de estos nombramientos queda claro cuando se discute el de un nuevo sacerdote para el Fortín de Areco. El gobernador expresa explícitamente en esa ocasión que no le interesan las opiniones políticas del candidato propuesto por Terrero, el Dr. Feliciano Martínez, porque le han dicho que es "retirado, moral y virtuoso sin hipocresía, y esto me basta". ${ }^{26}$ "Retirado" significa que Martínez no es propenso a participar de las lides políticas y que no ha de agregar turbulencias a una campaña que en los últimos años las ha tenido de sobra. Las recomendaciones que el gobernador dirige a los curas en estos años apuntan más

23 AGN X 4-8-6, carta del cura de San Pedro Mariano Espinosa a Rosas, 20 de abril de 1831.

24 AGN X 26-6-5. Jueces de Paz. Informes sobre unitarios y federales [1830-31 y 1851].

25 Saldías: Historia de la Confederación..., pág. 211. En la carta Rosas recomienda a Terrero: "Estimule usted, por Dios, a esos santos padres para que sirvan a su patria ahora que deben ser venerados como ministros del culto."

26 Ibídem. 
bien al desempeño del ministerio pastoral que a la prédica política: el 19 de mayo de 1830 Rosas le escribe a su padrino que

"El cura de Rojas no rezaba el rosario por la noche; tampoco echaba sus pláticas. Yo le hice ver que no era indispensable decirlas de memoria; que tanto valía escribirlas y leerlas en el púlpito. Él alegaba falta de velas, y yo lo allané todo". ${ }^{27}$

El deseo de orden signa también las instrucciones de carácter pastoral que envía el 3 de junio al cura de Arrecifes:

"El moralizar las clases de los pueblos, el hacer gustar á los fieles las preces y alabanzas que por su antiguedad y melodia son insinuantes al Corazon el acostumbrar la juventud de ambos sexos á los actos de piedad, entonando reunidos en el templo cansiones sensibles, me han movido á recordar el uso que en la Casa de Dios y en las de familia se frecuentaba antes diariamente en un rato del dia o de la noche. Me complacería de qe reviviese esa cristiana practica, de modo qe en todas las Iglesias parroquiales despues de rezado el rosario, se oyesen entonar las buenas noches, y en los sabados la Salve, como se acostumbrava antiguamente."

Aunque la doble tarea de "moralizar las clases de los pueblos" y de inculcarles prácticas religiosas "provechosas" no está reñida necesariamente con un encauzamiento litúrgico de la prédica política, el tono del discurso no posee en esos años la agresividad que adquirirá más tarde:

"Tambien la memoria del Gefe de la Provincia asesinado el trece de Diciembre de 1828, y la de los qe han fallecido en defensa de las leyes y en desagravio del atentado cometido contra la autoridad, seria muy conveniente recordarla diariamente después del Rosario, rezandosé en público un Padre nuestro con este objeto. Este recuerdo ayudaria á afirmar en los fieles el odio necesario á las sediciones, y el respeto á las leyes". ${ }^{28}$

Lo mismo puede decirse de una serie de medidas tendientes a la recuperación edilicia de los templos que toma Rosas durante esa suerte de recorrida político-pastoral por el norte de la provincia. ${ }^{29}$ En su carta del 15 de

27 Ibídem.

28 AGN, Secretaría de Rosas, X 23-9-4: 1830. Carta de Rosas al párroco de Arrecifes fechada el 3 de junio de 1830. Véase también Gálvez, M.: Vida de Don Juan Manuel de Rosas, Tor, Buenos Aires, 1949, pág. 121.

29 Incluso más allá de la frontera norte de la provincia: el 19 de junio de 1832 Rosas manda entregar al cura de Santa Fe "en moneda corriente, el equivalente á doscientos pesos metalicos destinados à beneficio dela Iglesia Matriz de dha Ciudad, pr ser uno delos compromisos contrahidos pr el infrascripto enel tiempo desu autorizacion como Comand.te Gral enla Campaña pa la restauracion delas Leyes.” AGN, Secretaría de Rosas, X 43-1-1: 1826-32. 
abril de 1830 a Terrero, tras expresarle al provisor su voluntad de hacer cuanto le fuera posible "por mejorar nuestras iglesias y las costumbres religiosas", Rosas manifiesta su indignación por el estado en que se hallaba la parroquia de San Pedro. ${ }^{30}$ Pocos días más tarde advierte que el templo de San Nicolás es incapaz de albergar a la feligresía del curato y decide ampliarlo, pero como las entradas de la fábrica son insuficientes y el tesoro de la provincia es incapaz de "subvenir en las circunstancias [presentes] à este objeto cristiano" concluye en que no es posible hacerlo sino con la ayuda de "las limosnas a q[u]e el corazon de los Fieles piadosos se prestaràn". ${ }^{31}$ Para recogerlas el gobernador inventa una institución en Buenos Aires que tendrá una larga historia: las comisiones de vecinos. En un buen número de parroquias rurales, Rosas conforma esas comisiones integradas por sujetos de su elección y presididas por el párroco local, dotadas de la facultad para recaudar limosnas en todo el territorio de la provincia. Las reformas alcanzan también, habitualmente, al cementerio y a la casa habitación de los curas. En algunos casos, como en San Nicolás, se autoriza la venta de bienes inmuebles. Análogas medidas toma Rosas respecto de otros pueblos e iglesias de la provincia, como Areco, Luján, Baradero, San Pedro, Salto, Rojas, Pergamino y Arrecifes: traslación del cementerio, reparación y/o ampliación de la iglesia y de la casa del cura, formación de comisiones presididas por el párroco para recaudar limosnas y financiar los trabajos, de acuerdo con el Departamento de Ingenieros. ${ }^{32}$

Pero tampoco la recuperación edilicia de las estructuras parroquiales cumple finalidades sólo religiosas: el 30 de abril de 1830 Rosas ordena desde San Nicolás que "los decretos de la autoridad", que como se sabe son "tan desconocidos à los habitantes de la campaña, como ignorados comunmente por los Magistrados en ella", sean fijados por los jueces de paz "en los puntos de mas concurrencia" y leídos "en la Parroquia perceptiblemente al tiempo de las misas que en ella hubiere, de suerte qe alcance a todos la luz necesaria sobre los decretos y disposiciones que se publiquen para su observancia y cumplimiento; no pueda pretestarse ignorancia, y se consigan los efectos de bien publico que forma los desvelos del Gobierno" ${ }^{33} \mathrm{El}$

30 "El templo de San Pedro era un chiquero. El cura lo había dejado cerrado, y le pido a usted que lo destituya en vista de que el tal cura se ha dado tiempo para edificar casas propias, y no para asear siquiera el templo.” Saldías: Historia de la Confederación..., t. I , 1968, pág. 211.

31 AGN, Secretaría de Rosas, X 23-9-1:1830, nota de 26 de abril de 1830.

32 AGN, Secretaría de Rosas, X 23-9-1: 1830.

33 AGN, Secretaría de Rosas, X 23-9-1: 1830. 
hecho de que las medidas en favor de las reparaciones de iglesias suelan ir acompañadas de otras referidas al mejoramiento del servicio de postas sugiere la conveniencia de interpretarlas como parte de la más general preocupación de Rosas por aceitar el sistema de comunicaciones provincial para ponerlo al servicio de su política de orden. El hecho de que la recorrida político-pastoral tenga lugar en el norte de la provincia, el área que ha sido más afectada por la guerra civil, es igualmente revelador de una preocupación por el orden que excede el marco estrictamente religioso.

Por otra parte, Rosas intentó fijar como propietarios a los párrocos que servían sus curatos interinamente, dejando de lado la celebración de los concursos prescriptos por las leyes canónicas y civiles, y que en sede vacante no era posible realizar. En 1830 Rosas se pronunció a favor de la estabilidad de los párrocos, alegando que la alta rotación de los curas no ayudaba precisamente a recuperar los espacios que la religión había perdido:

"La colocación de Curas Cristianos idoneos, i virtuosos, sin abusos, al frente de las
Iglesias de campaña resarciría en gran parte los quebrantos de que se resiente la obra
de la moral santa del Evangelio. Mas como los Curatos provistos interinamente, o en
Comisión no ofrescan sin la propiedad aliciente solido para servirlos, y contraerse á
los adelantamientos de las Iglesias con constancia y con aquel esmero qe excita la pie-
dad de los fieles, S. Ex.a ha tocado la importante necesidad de qe las provisiones inte-
rinarias cesen alli, adonde se encuentren Pastores que llenen las calidades que se
requieren para ser nombrados Curas en propiedad à quienes se les confiera colacion
canonicamente del Curato." ${ }^{34}$

En ese primer período de gobierno la política eclesiástica permanece firmemente anclada en los parámetros definidos por la reforma de 1822. Rosas recorre las "iglesias del Estado" y pone al "clero del Estado" al servicio de su política pacificadora. Se trata por supuesto del clero secular, incrementado desde 1822 con un significativo número de regulares secularizados. La transferencia de recursos del clero regular al secular había sido lograda con éxito suficiente y sólo había quedado en la provincia un corto número de franciscanos, prácticamente "atrincherado" en el convento. La "reducción a la unidad" había dado los resultados esperados. Rosas desconfía de ese clero secular, por otra parte cada vez más escaso a causa de las muertes de los ancianos y la caída del reclutamiento, por su tradicional indocilidad en relación con las autoridades tanto civiles como religiosas y

34 AGN, Secretaría de Rosas, X 23-9-4: 1830. 
sobre todo porque muchas de sus más conspicuas figuras en algunos casos han apoyado la gestión rivadaviana primero y la causa unitaria después. Por eso es que, ahora sí, en los primeros años de su segundo mandato Rosas interviene drásticamente para modificar la composición del clero de la provincia por medio de una purga bastante extendida de párrocos y capellanes acompañada de una "limpieza" más general de los empleados del Estado. ${ }^{35}$

Simultáneamente se intenta "clericalizar" al clero de la provincia acercándolo lo más posible al modelo ideal predominante en el universo mental intransigente. Claro ejemplo de este regreso a la disciplina es la carta pastoral que a comienzos de noviembre promulga el obispo sobre el uso del hábito talar. ${ }^{36}$ Allí se explica que durante las turbulencias de los últimos años

“....algunos de nuestro clero comenzaron á variar de su antigua moderación y decencia en el hábito y vestido que habian llevado anteriormente..."

El obispo, tras haber soportado esa pésima costumbre durante años, está decidido ahora a erradicarla de una vez, aprovechando el cambio político que ha acaecido en la provincia:

“...felizmente nuestra situación ha variado, y no hay ya cosa alguna que nos exima de responder á Dios y al público de nuestro silencio, cuando vemos y somos testigos de la infracción de los Sagrados Cánones, de la disciplina de la Iglesia, y de la costumbre mas autorizada que oculta su principio en la mas remota antigüedad. Tales son las que prescriben á los sacerdotes y demás clérigos inferiores, el hábito talar y decente que hoy se mira por algunos del clero con tanto desprecio, que parecen hacer alar-

35 Entre las primeras medidas que toma en el mismo mes de abril de 1835 figuran la de separar a Justo José Albarracín del curato de Santo Domingo, a Ramón Olavarrieta de la Merced y a Manuel José Albariño de la capellanía de gobierno. El 18 se separa a Vicente Arraga de Pilar en la campaña; el 20 a Nicolás Herrera de la capellanía del presidio y a Matías Chavarría de la capellanía del hospital de hombres. El 22, por último, Rosas pide al obispo la separación de Julián Segundo de Agüero, uno de sus más conspicuos enemigos políticos, del curato de la Merced. Luego de esa catarata de deposiciones la represión amaina, pero en junio vuelve a la carga ordenando desvincular a Santiago Rivas del curato de Quilmes. El obispo no da curso a estas órdenes con demasiado entusiasmo, en parte porque ve caer a algunos miembros del clero más afín a Roma (como Vicente Arraga), pero sobre todo porque se le hace cada vez más difícil encontrar quien suplante a los curas depuestos, en particular en la campaña. Así es que el 13 de octubre de 1835 Medrano escribe una carta al ministerio de gobierno para llamar la atención sobre la alarmante falta de clero que padece la provincia, que se conserva en AGN, Culto, X 4-9-4: 1835-1851.

36 El texto completo se encuentra en Digesto eclesiástico argentino. Recopilacion de leyes, decretos, bulas, pastorales, constituciones, etc. que se refieren a la Iglesia nacional..., Imprenta Especial de Obras, 1880, Buenos Aires, págs. 168-171: "Pastoral sobre uso de traje eclesiástico" del 1 de noviembre de 1835 . 
de en denigrar su respetable estado y carácter sacerdotal; para remediar este mal que es mirado aún por los mismos libertinos con asombro y escándalo, hemos determinado lo siguiente, en conformidad de lo que ordena el Santo Concilio de Trento..."

Medrano intenta, a través de la imposición de ese signo distintivo que es el hábito talar, disciplinar al clero secular, que la purga gubernamental y los destierros más o menos voluntarios han dejado en la provincia. Pero el viraje más importante se produce en otro plano: Rosas y Medrano intentarán invertir las prioridades de la reforma rivadaviana, transfiriendo esta vez recursos - materiales y simbólicos - del clero secular al regular. Uno de los motivos que animan esta decisión se relaciona con el hecho de que, tras los golpes recibidos en la década anterior, los religiosos sobrevivientes han abrazado con fervor la causa intransigente promovida por Roma, por el círculo de Medrano y por varios de los más influyentes colaboradores de Rosas. El viraje introduce una modificación significativa de la política eclesiástica porteña predominante desde la reforma de 1822.

Es interesante que a partir de la purga de clérigos de 1835 Rosas abandone la preocupación por la estabilidad en el servicio de los curatos que manifestara en 1830, un resultado adicional debido a su opción por una nueva modalidad de intervención eclesiástica basada en la acción del clero regular y en las misiones rurales. El viraje aparece límpidamente en los documentos posteriores a 1835. Rosas se declara más seguro de la eficacia de las fugaces misiones de los regulares que de la estable presencia de párrocos seculares, que a menudo se han demostrado poco dignos de su confianza. En 1837, en su carta dirigida al superior de los jesuitas, el Restaurador responde en los siguientes términos a un comentario del religioso en relación con la necesidad de establecer sacerdotes permanentes en los pueblos visitados durante la misión:

"En orden a los Sacerdotes que faltan en algunos Pueblos de campaña bien lo sabe, y lo tiene S.E., sobre su corazon; pero agrega que no vasta desear las cosas mas precisas para conseguirlas ú obtenerlas á satisfaccion de modo que el remedio nosea peor que el mal. Que poco a poco se va adelantando, y poco á poco con el favor de Dios nuestro Señor todo se ha de ir remediando". ${ }^{37}$

Los mismos resquemores habían sido manifestados unos meses antes en una carta en que el obispo había expresado su deseo de destinar a algu-

37 AGN, Culto, X 4-9-4: 1835-1851, Manuel Corbalán a Mariano Berdugo, 15 de noviembre de 1837. Las cursivas son mías. 
nos sacerdotes extranjeros al servicio de parroquias rurales vacantes. Rosas le había recomendado entonces la mayor prudencia, porque

"...es sabido las desavenencias que generalmente se susitan entre los curas, y feligre-
ses del campo en cuya virtud, menos malo es que no haya cura en un Pueblo de cam-
paña, que el qe lo haya en desabenencia con su feligrecia. En fin luego qe tome los
conosimientos que necesito contestare à V.S. Iltma por el organo del Señor Ministro
Arana"..$^{8}$

El viraje a favor de los religiosos y las misiones volantes se acompaña de una significativa transferencia de recursos del clero secular, personal de base del modelo reformista de 1822, hacia el clero regular que el experimento rivadaviano había casi extinguido. A mediados de octubre de 1835 Medrano solicita que se permita a los franciscanos abrir un noviciado, para lo cual cree preciso suspender por 10 años o más la Ley de Reforma y devolverles un claustro que había pasado a ser ocupado por la Universidad.$^{39}$ Con ello apuntaba a dotar a la diócesis de una estructura para la educación del clero bajo el control de una orden que tras la experiencia reformista había confirmado y fortalecido sus convicciones intransigentes. Rosas deja caer en el vacío, significativamente, la alusión a la derogación de la Ley de Reforma, pero acepta la idea del noviciado y le transfiere recursos de la universidad.

El intento de revertir la opción rivadaviana se explica además por un fenómeno ajeno a las vicisitudes rioplatenses: en 1835 están recalando en Buenos Aires religiosos expulsados por las reformas que introduce en España la regente María Cristina para no desperdiciar la colaboración de esos hombres imbuidos en general de un espíritu intransigente rabioso. La política desamortizadora que a partir de 1834 implementó el ministro Francisco Martínez de la Rosa, si bien similar a la que se puso en marcha en otros estados católicos, se vio acompañada por una oleada de inusitada violencia anticlerical. ${ }^{40} \mathrm{El} 17$ de julio de 1834 la creciente tensión derivó en tragedia con los motines de Madrid, durante los cuales se atacaron las casas

38 AGN, Culto, X 4-9-4: 1835-1851, Rosas a Medrano, 25 de abril de 1837.

39 AGN, Culto, X 4-9-4: 1835-1851, Medrano al Oficial Mayor del Ministerio de Gobierno, 13 de octubre de 1835 .

40 El proceso español ha sido abordado por una amplia bibliografía. Por ejemplo, Callahan, W. J.: "La destrucción de la Iglesia del Antiguo Régimen, 1833-1843", Iglesia, poder y sociedad en España, 1750-1874. Las líneas generales de la relación entre los estados católicos y los regulares en Rocca, G.: "Istituti religiosi in Italia tra Otto e Novecento", en M. Rosa, Clero e società nell'Italia contemporanea, Laterza, Roma-Bari, 1992, págs. 208-221. 
de los regulares y se asesinaron 78 jesuitas, franciscanos, dominicos y mercedarios. ${ }^{41}$ Vistos desde Buenos Aires, esos acontecimientos abrían la posibilidad de incorporar a algunos de los religiosos que huían del desastre para el servicio de la provincia. El 19 de agosto de 1836 Medrano le explicaba al nuncio en Río que "con motivo delas oscilaciones politicas dela Europa Española han llegado á esta Capital varios religiosos de las Ordenes de Sto. Domingo, San Francisco, San Agustin, Carmelitas, y Cartujos". ${ }^{42}$ Esa oleada de inmigración clerical de mediados de la década de 1830 trae a la provincia un número difícil de calcular de religiosos españoles que en algunos casos se incorporarán a los conventos locales. Algunos, incluso, serán destinados al servicio de parroquias por las que los clérigos nativos sentían irremediable aversión. Así es como en San Pedro en 1837 residía un sacerdote extranjero que según los jesuitas "apenas entendia el romance castellano". ${ }^{43}$ Otros probablemente vuelvan a España al apaciguarse las turbulencias políticas, como desde el principio le confiesan al obispo Medrano que es su intención ("piensan volver a la religión luego que en la España se aquieten las cosas...”). En 1835 el presidente del convento franciscano escribe al ministro de gobierno que un pequeño contingente de franciscanos que aguarda en Montevideo ha conseguido en España el permiso del gobierno para seguir viaje a Buenos Aires. ${ }^{44}$

Escapados de las convulsiones peninsulares, esos regulares llegan al Río de la Plata animados por una indestructible fe antiliberal que sintoniza bien con la guerra que Rosas ha declarado a sus enemigos políticos. Revelador de esa voluntad es el sermón de acción de gracias de Juan Antonio Argerich en ocasión de la restauración del convento dominico en 1835. Los religiosos, dice el orador, están llamados a actuar en la persecución de los enemigos del orden tal como su fundador Santo Domingo de Guzmán persiguió sin tregua a los herejes:

“...si hoy no existen Albigenses que convencer y convertir, existe un blanco mas fijo, al que debeis dirigir los tiros de vuestro celo piadoso: es preciso à toda costa desen-

41 Callahan: Iglesia, poder y sociedad..., págs. 152-154.

42 Carta de Medrano al nuncio fechada el 19 de agosto de 1836, Archivio Segreto Vaticano (en adelante ASV), Archivio della Nunziatura del Brasile (en adelante ANB), fasc. 268, cartella 3, ff. 127-128v.

43 Archivum Romanum Societatis Iesu (en adelante ARSI), Argentino-Chilensis 1001-I, "Relatio anonyma de annis 1836-1839", f. 25.

44 N. Aldazor al ministerio de gobierno, 5 de noviembre de 1835, en AGN, Culto, X 4-9-4: 1835-1851. 
mascarar el vicio y combatir la falsa sabiduría que nada dice al corazón: perseguir la irreligión y la impiedad, por los males que ha producido, y desorden que ha causado..."

Los regulares, que se han distinguido por su tesón en la lucha contra la impiedad y la heterodoxia, no deben cejar ahora en su deber de "segundar los esfuerzos de un Gobierno piadoso". Por eso Argerich se dirige también a los "hijos de Francisco de Asis" presentes en el templo para recordarles la resistencia que hubieron de oponer al "Gobierno impio" de los rivadavianos para no correr la misma suerte de los ahora redivivos. Ambas órdenes están llamadas a sellar una estrecha alianza contra la impiedad que reproduzca "...aquel tierno y fraternal abrazo que se dieron los dos Santos Patriarcas, cuando caminaban á un mismo objeto, animados del mismo celo.” 45

Como resultado de esa política de rescate de los regulares, el obispo y el gobierno cuentan a fines de 1835 con dos órdenes regulares, la franciscana y la dominica, bien dispuestas a apoyar esa proclamada restauración de los principios religiosos y políticos que encarna a la vez el sistema federal, exitoso además en la tarea de convertir discursivamente a sus enemigos en representantes de todas las depravaciones y escándalos. A ellas se suman al año siguiente los jesuitas. La posibilidad de concretar por fin el regreso de la Compañía, soñado en el seno de no pocas familias durante casi 70 años, pareció por fin realizable al producirse la segunda expulsión de los jesuitas de España en 1835. Mientras acaecían sangrientos episodios en España, en Buenos Aires se verificaban condiciones favorables para el retorno que el partido de la intransigencia no tardó en advertir: ese mismo año, en el sermón panegírico pronunciado el día de San Ignacio de Loyola, Mariano Escalada preparó el terreno llamando la atención de sus oyentes "sobre las ventajas que adqui[ri]ría nuestra Patria, si volviese a recibir en su seno a esta Santa Sociedad...”. ${ }^{46}$ Un año más tarde, desde el mismo púlpito, el mismo orador declaraba realizada la profecía de Zacarías:

45 Oracion pronunciada el domingo 8 de Noviembre de 1835, en la fiesta de accion de gracias que con asistencia del Ilmo. Obispo Diocesano celebraron los religiosos dominicos por el restablecimiento de su convento en esta ciudad por el presbitero Juan Antonio Argerich..., Imprenta del Estado, Buenos Aires, 1836, págs. 35-36.

46 Escalada, M.: "Sermón de Acción de gracias por el restablecimiento de la Ilustre Compañía de Jesús en la Ciudad de Buenos Ayres, y pronunciado el Domingo 6 de Noviembre de 1836, en la Iglesia Catedral, por Mons. Dr. Mariano de Escalada”, en F. Actis, El clero argentino. Oraciones fúnebres, panegíricos y discursos inéditos de Dr. Julián Navarro, Dr. Mariano José de Escalada, y Dr. José María Terrero, 1817-1854, Semanario “San Isidro”, San Isidro, 1927, pág. 152. El sermón del año anterior debe haber sido pronunciado el 31 de julio de 1835 . 
"El Ángel del Señor dijo: Señor de los ejércitos, ¿hasta cuándo no te apiadarás de Jerusalem? Este año es ya el septuagésimo. Por tanto esto dice el Señor: me volveré hacia Jerusalem con misericordia, y mi casa será edificada en ella. Mis ciudades aun abundarán en bienes."

En el septuagésimo año desde la expulsión decretada por Carlos III los jesuitas habían vuelto a Buenos Aires: Dios se había apiadado de Jerusalén y se restablecía el orden en su casa, poniendo de tal modo remedio a la llegada a tan remotas regiones del "funesto contagio de la impiedad nacida en Europa para desgracia del mundo entero" ${ }^{47}$ Con el regreso de los jesuitas, hecho de enorme impacto simbólico por el carácter emblemático de los ignacianos como defensores de las posiciones católicas más intransigentes y más "romanas", el dispositivo restaurador religioso basado en el clero regular cobraba su mayor solidez. En los padres de la Compañía, más que en los franciscanos y dominicos, depositarán su confianza tanto el gobierno de la diócesis como el de la provincia. En sucesivos decretos se transferirán a la orden los recursos necesarios para un eficaz desempeño de las tareas pastorales y educativas que Rosas y Medrano tenían en mente confiarles.

Entre ellas descuellan las misiones rurales volantes, que entre 1836 y 1839 realizan jesuitas y franciscanos como complemento de las visitas pastorales del obispo Medrano a distintos pueblos de campaña. ${ }^{48}$ El objetivo para la religión y para la causa federal es asegurar a esas almas rústicas aún no inficionadas —o no afectadas tanto como otras - por la "impiedad" y por la "filosofía del siglo". A esos predicadores de fugaz presencia pero más dignos de confianza se les exigirá además que prediquen sin ambages — ahora sí- las virtudes del gobernador y de la causa federal.

\section{Las misiones rurales}

Las misiones rurales siguen más o menos un mismo esquema. Se aprovecha para realizarlas la primavera, cuando han concluido los fríos, los caminos se secan y los campesinos no están todavía tan ocupados como lo estarán en enero con la cosecha del trigo. La que visitó el norte de la pro-

47 Escalada: "Sermón de Acción de gracias...”, págs. 136-137.

48 Cesáreo González a Francisco Javier de Lara, Buenos Aires, 19 de agosto de 1836, en ARSI, Arg-Ch., 1001, 1836-1847, II, 6. 
vincia en 1837-1838, por ejemplo, estaba compuesta por tres jesuitas —el superior Mariano Berdugo, el predicador Francisco Majesté y el Padre Miguel Cabezas-, a los que acompañaban en algunos tramos el obispo auxiliar Escalada y otros sacerdotes del clero secular. Era común además que a los misioneros y al párroco del pueblo se sumaran los sacerdotes residentes en el curato y a veces los curas de los pueblos vecinos. ${ }^{49}$ En San Fernando, donde la misión dura 14 días, tomaron parte el cura interino del pueblo Tomás Gomensoro - antiguo combatiente de la guerra revolucionaria-, el de San Isidro Cipriano Goneli — religioso secularizado durante la reforma- y los presbíteros Francisco Ferreira de la Cruz, José Antonio Picazarri y José Letamendi. ${ }^{50}$ La presencia del obispo Escalada permitía administrar el sacramento de la Confirmación, lo que en los pueblos de campaña no había ocurrido desde los tiempos de la visita del último obispo nombrado por la Corona, Benito de Lue y Riega, en 1803-1805.

Las actividades relacionadas con la misión se desarrollaban con el mayor boato posible y reproducían una secuencia ritual. El primer acto consistía en el recibimiento de los sacerdotes por parte de los vecinos más "respetables", que salían a caballo a buscarlos antes de que entraran en el poblado, generalmente en la frontera del partido, para desde allí escoltar la carroza hasta la entrada del pueblo. A veces los visitantes recibían importantes agasajos antes de llegar al núcleo urbano, como en San Pedro, donde Escalada y los jesuitas fueron invitados a comer un asado con cuero en una estancia. ${ }^{51}$ Ese recibimiento fuera del poblado tenía lugar también en ocasión de las visitas episcopales: en esos mismos meses la del obispo Medrano a San Andrés de Giles fue escoltada desde la frontera del partido hasta el pueblo por

49 El juez de paz de San Isidro a Rosas, San Isidro, 14 de octubre de 1837, en La Gaceta Mercantil, 16 de octubre de 1837: "Crée el infraescrito que /.../ faltaría á un deber de justicia sino elogiase debidamente el celo con que ha cooperado á esta Santa Mision el respetable Cura Vicario de esta Parroquia, pudiendo decirse que por su asidua asistencia al confesonario ha trabajado á la par de los PP. Misioneros. Tambien han prestado interesabtes servicios los Sres. Presbíteros D. Francisco Ferreira de la Cruz y D. Narciso Mansilla residentes en este Pueblo, y últimamente al Sr. Presbítero D. José Antonio Picazarri, que en el coro, y confesonario ha contribuido al decoro de las funciones y consuelo de los fieles". La restante información sobre la visita a San Isidro, salvo indicación contraria, proviene de la misma fuente.

50 El juez de paz de San Fernando a Rosas, San Fernando, 2 de noviembre de 1837, en $L a$ Gaceta Mercantil, 4 de noviembre de 1837. La restante información sobre la visita a San Fernando, salvo indicación contraria, proviene de la misma fuente.

51 El juez de paz de San Pedro a Rosas, San Pedro, 21 de diciembre de 1837, en La Gaceta Mercantil, 26 de diciembre de 1837. La restante información sobre la visita a San Pedro, salvo indicación contraria, proviene de la misma fuente. 
“...98 vecinos á caballo de los mas lucidos del partido, federalmente vestidos, y el Sr. Comandante de la Compañía de Milicias D. Pascual Rodriguez, con 40 de sus milicianos en caballos blancos, trayendo todos sus divisas federales colocadas al lado izquierdo frente al corazon, y con testera y colera punzó todos los caballos". ${ }^{52}$

La comunidad de ciudadanos/feligreses, representada por sus más lucidos exponentes, acompañaba a los misioneros o al obispo en visita pastoral hasta el punto en que se producía la recepción por parte del pastor local, con lo que se daba comienzo oficial a la misión o visita episcopal. El párroco, acompañado de lo más granado de su grey, salía a pie del templo cargando la cruz parroquial a recibir a los misioneros o al obispo a las puertas del poblado. En San Isidro

“...hicieron los Padres su entrada en este pueblo á pie, en su trage propio de Misioneros, con cruces altas en las manos y un pendon que representa la Sagrada Imagen de la Sma. Virgen. El Sr. Cura Vicario con una gran parte de su feligresía salió á recibirlos procesionalmente, llevando la devota efigie del Señor Crucificado. El P. Superior lo recibió arrodillado á la distancia en que se encontraron, y desde alli se dirijieron á la Iglesia cantando con todo el pueblo las letanias de los santos, y concluidas, tuvo lugar la apertura de la Misión..... 53

El párroco otorgaba su consentimiento para la realización de las actividades propias de la misión delegando la cruz parroquial, símbolo del mandato pastoral, al responsable de la expedición misionera. Tan importante era ese gesto que cuando no había párroco otro sacerdote tenía que hacer sus veces. En ocasión de la visita de Medrano a San Andrés de Giles, donde la parroquia estaba vacante, uno de los acompañantes del prelado abandonó la carroza antes de llegar al pueblo y se adelantó a caballo hasta la iglesia para revestirse y "representar" al cura durante la recepción del obispo.

Normalmente la misión duraba entre 10 y 15 días, aunque en algún caso excepcional, como lo fue el de la ciudad de San Nicolás de los Arroyos, podía extenderse hasta alrededor de un mes. La duración guardaba relación con la entidad demográfica del pueblo visitado. Durante esos días los misioneros se ocupaban básicamente de confesar, enseñar la doc-

52 El juez de paz de San Andrés de Giles al oficial mayor del ministerio de gobierno Garrigós, 12 de diciembre de 1837, en La Gaceta Mercantil, 14 de diciembre de 1837. La restante información sobre la visita a San Andrés de Giles, salvo indicación contraria, proviene de la misma fuente. de 1837 .

53 El juez de paz a Rosas, 14 de octubre de 1837, en La Gaceta Mercantil, 16 de octubre 
trina cristiana a los niños, participar de recitaciones colectivas del Rosario y predicar. En San Fernando, luego de las confesiones que tenían lugar desde antes del alba y hasta el almuerzo, cada día por la tarde

\footnotetext{
"a la doctrina seguía el santo Rosario, despues la Plática doctrinal y moral; y en seguida, el recuerdo devoto y piadoso a las cinco sagradas llagas de Jesu-Cristo, concluyendo con un elocuente Sermon, teológico y moral, alusivo á los diez Mandamientos del decálogo, preceptos de nuestra Santa Madre Iglesia, y deberes del hombre en Sociedad." ${ }^{54}$
}

La misión se concebía como restauración de un orden moral, político y religioso. La "restauración de las leyes" con que se había puesto remedio a la acción subversiva de los unitarios se complementaba con la recuperación de los valores tradicionales y religiosos perdidos. La concordia en el seno de las familias era a la vez base y figura de la armonía social. El juez de paz de San Fernando consigna que los misioneros

“...han cooperado á unir todos los matrimonios que estaban desunidos, y casar todos los que estaban viviendo escandalosamente; a ensanchar y ratificar la opinion Federal de este vecindario, demostrando moralmente los indecibles bienes que a proporcionado a todos los estados en general. Ellos han edificado los espíritus de este vecindario en las sagradas máximas de nuestra religion santa...". 55

En igual sentido se pronuncia el juez de paz de San Nicolás de los Arroyos, que da fe de que el obispo Escalada "ha desobligado á infinitos infelices, ha unido algunos matrimonios, y ha hecho se casen infinitos, que vivian escandalosamente". ${ }^{56}$

Al finalizar la misión, antes de abandonar el pueblo, los misioneros erigían una cruz en las afueras, en el cementerio o en la misma plaza, con el objeto de que al verla, los fieles recordasen la visita, los sacramentos recibidos y los contenidos de las predicaciones. Esos contenidos, a diferencia de los que Rosas había propuesto durante su primer mandato, adquirieron durante el segundo claras connotaciones facciosas. Rosas parece más convencido que antes, en esta nueva etapa, de que las pláticas y sermones constituyen valiosas herramientas para la construcción del orden federal y

54 El juez de paz a Rosas, 2 de noviembre de 1837, en La Gaceta Mercantil, 14 de noviembre de 1837. El subrayado es mío.

55 Ibídem.

56 El juez de paz de San Nicolás de los Arroyos a Rosas, 20 de enero de 1838, en La Gaceta Mercatil, 29 de enero de 1838. La restante información sobre la visita a San Nicolás de los Arroyos, salvo indicación contraria, proviene de la misma fuente. 
el combate de sus enemigos. Vale la pena introducir una breve digresión sobre este punto.

Rosas, en efecto, imparte en esos años reiteradas instrucciones a las autoridades religiosas de la diócesis o directamente a algunos párrocos para que el púlpito no permanezca ocioso. En 1836 el ministro de gobierno Garrigós cursó al obispo una nota dedicada enteramente al tema. Allí se informaba al prelado que el gobierno consideraba que "para hacer frente de un modo completo á las pèrfidas sugestiones de los impios unitarios, y para que cada dia se arraigue mas y mas en los corazones de los porteños su adhesion al règimen federal de la República" esperaba que el obispo tuviese a bien

"expedir un decreto, que seria conveniente se fijase en las sacristias de todas las iglesias, mandando á los individuos del clero secular y regular, que cuando menos, al fin de todas las pláticas y sermones, aunque sean panegíricos, dirijan al pueblo una exhortacion para que se mantenga firme en el sosten y defensa de la expresada cau$s a$, por las muy justas, morales y religiosas razones que van indicadas; y que le hagan entender en ella la obligacion en que está cada uno de propender en cuanto pueda al crédito y lustre de esta gran causa nacional, no solamente prestando por su parte sumisa obediencia a las leyes, y sincero respeto a los magistrados, sino tambien cuidando de llenar pública y privadamente los deberes que segun su estado y condición le imponen la moral y la religion cristiana".57

En los años sucesivos Rosas volvió a intervenir con instrucciones relativas tanto a la frecuencia como a las modalidades y contenidos de la predicación. En julio de 1837 el edecán informaba al juez de paz de Pilar sobre una nota que se cursaría al obispo para que enviase a los curas

"una circular, respe[c]to de exhortaciones (que algunos descuidan faltando á lo mandado) a los fieles sobre el uso de la divisa, y muy especialmente á las mugeres, como también sobre un padre nuestro por el alma del finado Exmo. Señor Gen[ra]l. D. Juan Facundo Quiroga, luego de rezarse el q[u]e tiene lugar por la del finado nuestro Gob[erna]dor. el Ex[celentísimo]mo. Sor. D. Man[ue]l Dorrego..."

Mientras tal medida arrojaba los resultados esperados, se ordenaba al juez de paz que

“...lo vea V. al Señor vicario del punto de parte de SE y le muestre esta nota para que se persuada de la necesidad de una y otra cosa p[ero] con especialidad de asustar á

57 Garrigós al obispo, 7 de diciembre de 1836, Registro Oficial del Gobierno de Buenos Aires. Libro decimo-quinto. 1836, Imprenta del Estado, 1836, Buenos Aires, págs. 165- 167 (el subrayado es mío). 
las mugeres con que en ultimo resultado, no se permitira entrar en la Iglesia á las que se obstinaren en hacerlo sin la divisa." ${ }^{8}$

Digamos de paso que esa fijación de Rosas con la predicación logró incluso atraer la atención de las autoridades romanas, que no tardaron en asociarla a otras rarezas suyas, interpretadas todas como indicios preocupantes de la incipiente insania mental de la que parecía prisionero. En una nota dirigida al Secretario de Estado, el nuncio en Río de Janeiro aseguraba que el gobernador porteño se encontraba "en gran peligro de volverse loco y loco furioso", lo que resultaba evidente en la práctica de exponer su retrato en las iglesias, pero también en la obligación de que

“...en el Púlpito los Predicadores, al exhortar a la obediencia de las Leyes, y de los Magistrados, no se limiten a dar recomendaciones generales, sino que hablen de Él, como del benemérito de la Patria, al cual todos deben todo tipo de reverencia y sumisión". 59

Los pocos datos con que contamos sobre los contenidos predicados en las misiones rurales resultan por demás elocuentes. En las de 1837-1838 el sacerdote designado para la predicación diaria fue el jesuita Francisco Majesté, que ganaría fama a partir de entonces por su elocuencia y por su adhesión al régimen federal, en la que perseveró hasta las postrimerías del régimen. El último día de la misión en San Isidro Majesté

"pronunció un elocuente discurso el mas análogo al objeto, tomando de aquel interesante acto, un fuerte argumento para demostrar a tan numeroso auditorio los bienes que resultan á esta Provincia del paternal Gobierno de V.E. y las ventajas que ha ocasionado á nuestra Santa Religion, la Nacional, y justa causa de la Federacion. Estas ideas que habia anunciado ya en sus anteriores sermones con un vivo interes, la extendió brillantemente en este, pues que los buenos resultados de la mision que cerraba en aquel acto, y el augusto monumento que acababa de erigirse con tanta gloria de la Religion, como humillacion de la impiedad, solo han podido verificarse bajo la benéfica influencia del sistema Federal. Ésta es una verdad que está gravada en los corazones de estos habitantes quienes bendecirán siempre á la Federacion y á V.E. porque

58 Borrador de nota de julio de 1837, AGN, Juzgado de Paz de Pilar, X 21-4-1: 1830-1851. Idéntica nota se envió al Juez de Paz de San Isidro el 7 de julio de 1837: AGN, Juzgado de Paz de San Isidro, X 21-6-4: 1828-1840 (el subrayado es mío).

59 ARSI, Arg-Ch., 1001, 1836-1847, VII, 22, 24 de diciembre de 1841. La primera cita en italiano dice textualmente que Rosas se encuentra "in gran pericolo di diventar pazzo e pazzo furioso". La segunda, que obliga a que "...sul Pulpito i Predicatori, in raccomandar l'obbedienza alle Leggi, ed ai Magistrati, non si tengano sulle generali, ma parlin di Lui, come di benemerito della Patria, a cui si debba da tutti ogni riverenza e sommessione." 
amas de los innumerables bienes con que los ha favorecido, les ha proporcionado el inmenso bien espiritual de esta Santa Mision". ${ }^{60}$

El mismo sacerdote abrió la misión de San Fernando pronunciando un "elocuente Sermon moral" en el que hizo alusión

“...al vivo deseo de este Pueblo, y pedido para la venida de la Santa Mision, en cuyo brillante discurso sobresalieron los clásicos argumentos del paternal Gobierno de V.E., y su piedad religiosa del deber primario de todo buen patriota Federal y moralidad santa como el único medio de sostener esta Causa Santa y justa...". ${ }^{61}$

Asimismo, la inauguración de un nuevo cementerio por parte de los misioneros al finalizar la visita le otorgó una nueva oportunidad de predicar

“...convincentemente los palpables beneficios obtenidos por todos los habitantes de la Provincia, del actual paternal Gobierno de V.E., de sus trabajos é incesantes desvelos por el bien general, propagacion de nuestra Santa religion, y sosten de la justa causa Nacional de la Federación, que con tanta dignidad han proclamado los pueblos de la República Argentina....". ${ }^{2}$

En ese mismo discurso, esgrimiendo "razones científicas e incontestables", el jesuita se demostró capaz de mostrar incluso que federación y religión no eran más que una misma cosa. Si por un lado "solo en el actual sistema federal, y bajo la influencia de un Gobierno piadoso y religioso, podian haberse obtenido bienes de inconmensurable importancia, y el triunfo completo de nuestra sagrada religion", por otro, era imposible "poder ser un verdadero patriota federal, separándose de los principios religiosos, y de la luminosa senda del santo evangelio".

\section{Senderos que se bifurcan}

El hecho de que Majesté residiera en Buenos Aires hacía apenas un año -y tal vez poco más que se había enterado de su localización exacta, e incluso de su existencia - no constituyó un obstáculo para que abrazase ardorosamente la causa federal del Restaurador de las Leyes. Pero debajo de 1837.

60 El juez de paz a Rosas, 14 de octubre de 1837, en La Gaceta Mercantil, 16 de octubre de 1837

61 El juez de paz a Rosas, 2 de noviembre de 1837, en La Gaceta Mercantil, 14 de noviembre

62 Ibídem. 
del púlpito improvisado en la plaza, el superior de la comunidad alimentaba recelos y malestares que en breve harían estallar las discordias que conducirían al fin de la experiencia. En esa ruptura se expresa la contradicción básica que condujo al fracaso de la política eclesiástica de Rosas: la resurrección de los regulares, que implicaba la re-fragmentación de la obediencia y del imaginario religioso, se verificaba en el marco de la vigencia de una ley que señalaba los límites dentro de los cuales el nuevo clero habría de actuar y el fallido viraje intransigente habría de verificarse. La reintroducción de lazos de dependencia respecto de las autoridades residentes fuera de la provincia y la recuperación de los vínculos que ligaban a segmentos de la feligresía porteña con las órdenes religiosas eran inconciliables con el modelo de base. Ese viraje naufraga por lo tanto por las contradicciones que introduce el intento de Rosas de realizar esa operación de rescate sin renunciar a los rasgos generales del esquema rivadaviano de reducción a la unidad. Es sugestivo que también en las demás órdenes se hayan producido desórdenes y rupturas. Tal vez un indicio de ello sea el malestar análogo que habitó a una parte de la comunidad jesuítica por el decreto del 12 de febrero de 1838 con el que el gobierno ordenó la expulsión de un grupo de franciscanos españoles que, recibido años atrás con los brazos abiertos, últimamente había intentado expulsar de la provincia. ${ }^{63}$ Lo cierto es que los religiosos que escapaban de las reformas y violencias de la Península encontraban en Buenos Aires una política eclesiástica en algunos puntos demasiado cercana a la que había dado origen a sus persecuciones y desdichas. En cualquier caso, es claro que si las comunidades de franciscanos y dominicos lograron sobrevivir a las presiones del rosismo, fue gracias a su capacidad para adaptarse a las exigencias del gobierno.

Los límites de la política eclesiástica de Rosas pueden advertirse también en los conflictos que alejan a monseñor Mariano Escalada y a una parte de la comunidad jesuítica de las simpatías del Restaurador y de su entorno más inmediato. Las convicciones intransigentes de Escalada o del superior Berdugo chocan con las ambigüedades de Rosas con relación a los ejes fundamentales que caracterizaban las convicciones de galicanos e

63 En abril de 1837 el gobierno tiene que intervenir para garantizar la disciplina del convento de San Francisco y en septiembre de 1838 le toca hacerlo en Santo Domingo. En ambos la llegada de religiosos europeos ha producido agudos conflictos, por lo que el gobierno debe advertirles que está dispuesto a extender "a lo interior del claustro el brazo de la autoridad que le esta confiada pa la conservacion del orden social". Los documentos se encuentran en AGN, Culto, 4-9-4: 1835-1851. El decreto de expulsión de los franciscanos está en Registro Oficial del Gobierno de Buenos Aires, 1838, págs. 17-20. 
intransigentes. El superior de la Compañía estaba equivocado cuando en 1837 interpretaba que

“...nos hemos colocado en una posicion ventajosa en medio de los dos partidos [unitario y federal, RD], que no nos miran sino como ministros de una religion que por nuestra conducta han conocido (dicen) que es independiente de los sistemas politicos". ${ }^{64}$

En 1841 esa ilusión se había evaporado, como atestigua, entre otros documentos, la siguiente carta del mismo Padre Berdugo:

\begin{abstract}
"Por la otra Carta que remito adjunta verá VR el termino fatal que ha tenido la aversion de ánimo que contra nosotros empezó á concebir muchos meses hace el Presidente de la Republica de Buenosaires, porque no accedíamos a ser unos viles instrumentos de su tortuosa politica: unido en miras e intereses con alguna parte de aquel clero que se muestra poco adicta á la Silla Apostolica, nada menos pretendia que obligarnos á profanar el altar del Señor y a separarnos de nuestra inmediata dependencia de Roma..." [...] "Nuestro Colegio y nuestro Seminario de educación se cerraron el dia 10 del pasado Octubre; y no es mi animo describir aqui las viles maquinaciones de que los agentes de uno y otro partido adverso se valieron para concitar los animos de la población contra nosotros, para sublevar la plebe y para amedrentarnos con amenazas de muerte, con griterias alrededor de nuestra casa, y con insultos y oprobios de toda especie: parecia que se habian propuesto repetir la horrible escena del famoso dia 17 de Julio de 1834 en Madrid...".65
\end{abstract}

La percepción de Berdugo, que ve a Rosas "unido en miras con alguna parte de aquel clero que se muestra poco adicta á la Silla Apostolica", refleja la ambigüedad del gobernador respecto de las posiciones intransigentes que había alentado años atrás. El conflicto nace de las presiones para alinear a los jesuitas políticamente, por un lado, y por otro de la creciente renuencia de las autoridades civiles y religiosas a aceptar las consecuencias concretas de la reintroducción en la Iglesia porteña de un modelo de obediencia fragmentada. El problema con Berdugo, según sus propias palabras, no atañe específicamente a su persona sino a su carácter de "cabeza del cuerpo". El cuestionamiento apunta a imponer a la comunidad el modelo de Iglesia de Estado, lo que implicaba el cercenamiento de su autonomía como "cuerpo" y la ruptura con las autoridades extraterritoriales. Berdugo se refiere en la misma carta a un eclesiástico

64 ARSI, Arg-Ch., 1001, 1836-1847, IV, 3: copia de carta de Berdugo al P. Morey, Buenos Aires, 30 de abril de 1837 .

65 ARSI, Arg.-Ch., 1001, 1836-1847, VII, 19: copia de carta de Berdugo, sin destinatario, fechada en Montevideo el 12 de noviembre de 1841 (el subrayado es mío). 
“...a quien sorprendí envolviendo al pobre Obispo, y abusando de nuestra afliccion el dia 5 estrechando las cosas para que yo y los míos reconociésemos su jurisdicción y nos separásemos de la Unidad de VRR....”. ${ }^{66}$

En suma, para Rosas, en tanto que gobernador, la Iglesia es Iglesia del Estado, un segmento de su aparato político-administrativo, y los eclesiásticos son empleados públicos como todos los demás. Esta herencia rivadaviana pesa en Rosas mucho más que cualquier otra consideración. Por eso su política religiosa resulta incomprensible o contradictoria cuando se la piensa en términos de "apoyo a la Iglesia" o de "relaciones entre el Estado y la Iglesia": Rosas considera a la Iglesia porteña en el marco político-institucional que ha creado la reforma de Rivadavia de 1822. Las interpretaciones que desde la vertiente católica recogen el affaire jesuita de esos años omiten este dato insoslayable y proponen la imagen de un Rosas que parece enloquecer, que deja de pronto de proteger a la "Iglesia" para comenzar a atacarla a causa de su tendencia a confundir con la política los sacrosantos derechos de la religión. ${ }^{67}$ Se pierde de vista en esa mirada que los jesuitas, como los franciscanos o dominicos españoles, han sido invitados a la provincia de Buenos Aires para incorporarse a su clero como empleados del Estado; es esto lo que Rosas piensa y Berdugo no entiende; es esto lo que lleva a la ruptura de Berdugo con Rosas y con el padre Majesté, que sí comprende, asimila y acepta la invitación que el Restaurador ha dirigido a la entera comunidad ignaciana.

El gobernador de la provincia no se convierte en un perseguidor de la Iglesia, no transmuta de Constantino a Dioclesiano: simplemente exige a quienes ha invitado a incorporarse al clero del Estado, a quienes ha concedido el uso de un establecimiento del Estado, a quienes ha decidido subvencionar con fondos del Estado, que sirvan sin ambages a ese Estado. El rechazo de Rosas de la idea de la Iglesia como "sociedad perfecta", como entidad diferenciable y diferenciada del Estado, se revela en su negativa a derogar la ley de reforma del clero, que tantas voces cercanas le sugieren, y en el plano simbólico en su desinterés en la propuesta de Medrano de

66 Ibídem (el subrayado es mío).

67 Pérez, R.: La Compañía de Jesús restaurada en la República Argentina y Chile, el Uruguay y el Brasil, Henrich y Cía, Barcelona, 1901; Hernández, P. La Compañía de Jesús en las repúblicas del sur de América, Barcelona, 1914; Tanzi, H.: "Relaciones de la Iglesia y el Estado en la época de Rosas (Estudio de antecedentes constitucionales del Derecho de Patronato en nuestro país)", Historia, 30, 1963, págs. 5-28; Castagnino, R. H.: Rosas y los jesuitas, Pleamar, Buenos Aires, 1970; Avellá Cháfer, F.: "El uso de la divisa punzó en la Confederación Argentina. Aspecto eclesiástico", Nuestra Historia, 9, 1970, págs. 143-150; Bruno: Historia de la Iglesia en Argentina... 
modificar la fachada de la catedral, que expresaba arquitectónicamente las concepciones de los reformistas rivadavianos, para acercarla más a los cánones estéticos del catolicismo intransigente. El proyecto incluía el agregado de dos campanarios y de nichos con imágenes que atenuaran su aspecto de templo griego. ${ }^{68}$ Ese rechazo refleja los límites de la apertura del Restaurador a los planteos y a las concepciones de la corriente intransigente, su negativa a considerar a la Iglesia provincial como una entidad diferente del Estado mismo.

La gran contradicción que atraviesa la transferencia de recursos del clero secular al regular, reversión opuesta a la que había constituido el meollo de la política rivadaviana, estriba en que esa operación tiende a reconstituir un andamiaje de obediencias fragmentadas y una concomitante descentralización devocional que instalan un elemento de tensión con el modelo de Iglesia republicana, centralizada e incorporada al Estado, al que Rosas no ha renunciado de ninguna manera. Los sucesivos conflictos con los jesuitas, con los dominicos y con los franciscanos revelan el malestar que genera esa tensión, que Rosas trata de resolver, en el caso de los primeros, estimulando la ruptura de la comunidad y desplazando a los religiosos más reacios a incorporarse sin más al clero de la provincia; es decir, deshaciéndose de aquellos que guardaban obediencia al padre Berdugo. La situación interna de la comunidad no es, sin embargo, responsabilidad exclusiva de Rosas: en su seno habitaban ya tensiones entre algunos de sus miembros, celos y recelos personales que se expresaron a la postre en una diferente recepción de la política del Restaurador. Las diferencias entre el superior Mariano Berdugo y el Padre Francisco Majesté estaban animadas por cuestiones que iban más allá de las meramente políticas, como revelan los documentos que custodia el archivo de la Compañía. La segunda expulsión de la Compañía de Buenos Aires es el resultado de esa incomprensión:

"Los Padres de la Compañia de Jesus, sin embargo de sus virtudes cristianas y morales, reunidos en comunidad y sugetos a la obediencia de un Superior opuesto a los principios políticos del Gobierno, no han correspondido las esperanzas de la Confederacion, consignadas valientemente en el decreto de su restitucion- Su marcha de fusion opuesta al sentimiento federal, desagradaba altamente mucho ha la opinion pública, contenida por los respetos del Gobierno- Pronuncióse despues fuertemente, y los Padres de suyo dejaron el Colegio". ${ }^{69}$

68 Aliata: "Cultura urbana..."

69 Registro Oficial del Gobierno de Buenos Aires, 1841, pág. 157. (1523): "Mensage a la Decima-Nona Legislatura”, 27 de diciembre de 1841. 
A partir de 1838-1839, con el bloqueo francés, la sublevación de los "Libres del Sur" —en la que participan varios eclesiásticos - y las muertes de los Maza, Rosas muestra cada vez menos paciencia a los miembros del clero que no comprenden lo que de ellos se espera. ${ }^{70}$ Esa pérdida de paciencia, a la vez, parece ir acompañada de una paralela decepción del gobernador respecto de la eficacia de ese segmento del Estado - la Iglesia - en la coyuntura mucho más violenta que se va instalando. Si en 1829 o en 1835 Rosas se proponía a sí mismo como Restaurador de las Leyes, del orden y de la religión, en 1839 los discursos que más aprecia el gobernador se radicalizan demasiado como para ser digeridos por hombres de la mesura de Escalada o Berdugo. En ese año para el cura de San Nicolás de los Arroyos, los enemigos de Rosas lo son también, sin mediación alguna, del poder de Dios, y el gobernador es "semejante a aquella columna de fuego que, según la historia, guiaba por el desierto al pueblo de Dios". ${ }^{71}$ En ese contexto no hay margen para la más mínima ambigüedad, y los jesuitas españoles más intransigentes, que tan sólo cuatro años antes Rosas había juzgado útiles agentes del orden, le parecen ahora más un problema que una solución. La escasez de documentos referidos a cuestiones eclesiásticas de la década de 1840 y el carácter rutinario y burocrático de los que han llegado a nosotros, salvo pocas excepciones, no nos ayudan mucho a interpretar la etapa que se abre desde entonces. Pero es significativo que a partir de esos años el gobierno deje de promover las misiones rurales y de tomar medidas tendientes a fortalecer al clero regular con recursos materiales y humanos. Tal vez otros segmentos del Estado - pienso en el ejército- hayan resultado a los ojos de Rosas más eficaces o confiables para garantizar la defensa del orden federal.

Recibido el 17 de octubre de 2005 Aceptado el 15 de enero de 2006

70 Véase los interesantes datos sobre la participación de clérigos en la sublevación y sobre algunas de sus derivaciones políticas en Carranza, Á.: Bosquejo histórico del Doctor Cárlos Tejedor y la conjuracion de 1839, Imprenta de Juan A. Alsina, Buenos Aires, 1879, en particular págs. 17, 4344, 46, 150-162, 171-173, 191 y 194-195.

71 El discurso en Saldías: Historia de la Confederación..., pág. 120. Luego de las frases citadas la exhortación continúa de manera por demás elocuente: "Éste es Rozas. [...] Corramos a recibir órdenes de nuestro magistrado e impartiéndonoslas, grabemos en nuestros corazones este lema: ¡Odio eterno a los parricidas unitarios vendidos al inmundo oro francés! ¡Odio y venganza en el pecho federal contra los incendiarios esclavos de Luis Felipe!". 